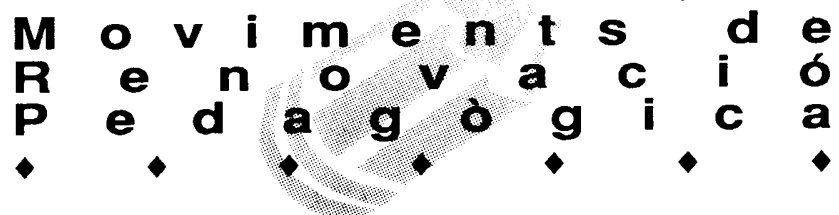

\title{
DEL PROJECTE 100 MESURES PER MILLORAR L'ENSENYAMENT A LA CONVOCATÒRIA DEL CONGRÉS DE LA RENOVACIÓ PEDAGÒGICA
}

\author{
Moviment de Renovació Pedagógica del Camp de Tarragona
}

Amigues i amics: tant per promoure debats i actuacions en temes de formació permanent, com en altres aspectes de la realitat educativa del nostre país, i després de dos anys de debat en què hem realitzat més de cinquanta presentacions, hem cregut convenient posar en marxa el Projecte 100 mesures per millorar l'ensenyament. Aquest projecte s'ha presentat, pràcticament, a totes les comarques de Catalunya, als sindicats CCOO, USTEC, STE's iUGT; a les federacions d'associacions de pares; als partits polítics Convergència Democràtica, Esquerra Republicana, Unió Democràtica, Partit dels Socialistes i Iniciativa per Catalunya i a d'altres entitats educatives.

Com a fita d'aquest procés que endeguem ara, creiem possible la convocatòria d'un Congrés de la Renovació Pedagògica, a celebrar en el termini aproximat de tres anys, que serveixi com a primer punt d'arribada d'un procés que volem ric i creatiu, on es puguin incorporar i articular el conjunt d'experiències i propostes de millora educativa. Un congrés que suposi la recuperació, per part de la societat civil i la comunitat educativa, de la iniciativa en la millora educativa.

Per tal de difondre aquesta convocatòria hem elaborat el següent manifest.

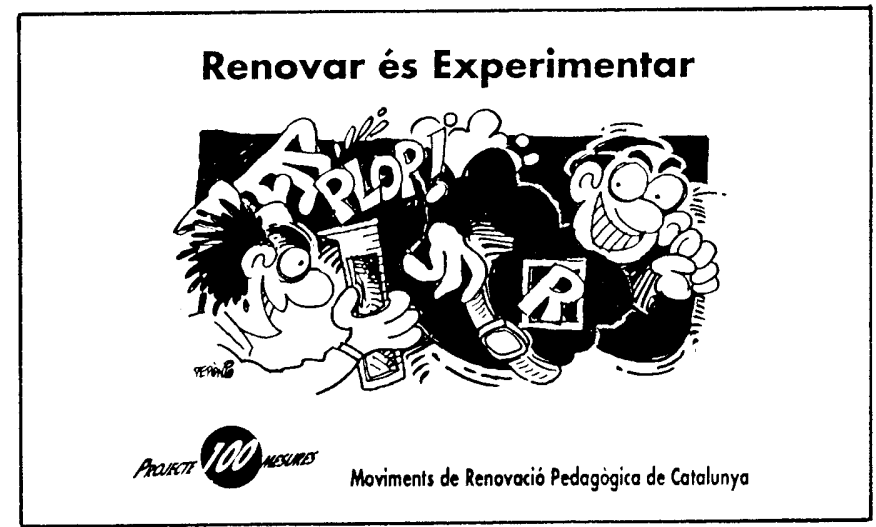

\section{Manifest del Primer Congrés de la Renovació Pedagògica}

Nosaltres, mestres de tots els nivells educatius, pares i mares, alumnes, organitzacions i entitats, convocats per la Federació de Moviments de Renovació Pedagògica, ens hem aplegat a Lloret de Mar, davant del vell Mediterrani (fent nostres les paraules del poeta Pessoa "O Mediterraneo, doce, sem mistério nenhum, clássico, um mar para bater/De encontro a esplanadas olhadas de jardins próximos por estátuas brancas! [E] Mediterrani, dolç, sense gota de misteri, clàssic, un mar per aiguabatre / terrasses sotjades des de jardins propers per blanques estàtues!]) per aprovar aquest

MANIFEST que proposem a la societat catalana perquè se'l faci seu:

Que vivim un temps de canvis constants que ens obliga a ressituar la funció de l'escola, canvis que afecten tota la diversitat de temes que hi conflueixen.

Que aquests canvis, lluny d'espantar-nos, ens porten a augmentar el nostre dinamisme per anar fent realitat la vella utopia de construir una escola al servei de tots els nens i nenes, de tots els nois i noies de Catalunya.

Que reivindiquem la utopia i ho fem molt conscientment i més ara quan sembla que la societat ens aboca a enterrar els vells somnis i a situar les nostres esperances no més enllà del nas.

Que aquesta reivindicació la fem amb els peus ben posats a terra, perquè sabem que només podem construir partint del que som, tenint molt clar d'on venim i sabent explicitar, en la mesura del que sigui possible, on volem anar. 


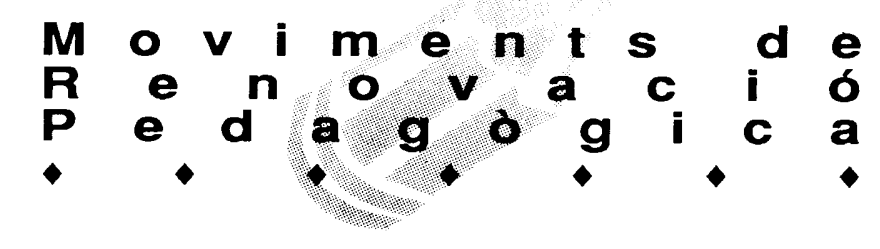

Que assumim plenament el nostre passat. Que els encerts que hem tingut ens empenyen a tirar endavant i que els errors o les marrades ens ajuden a trobar nous camins d'actuació.

Que el nostre objectiu és la millora de la qualitat de l'escola com a servei i que aquest treball el fem contra vents i marees que dificulten o encallen la nostra labor quotidiana.

Que estem disposats a continuar treballant per la millora del nostre sistema educatiu, sense parcel.lar la realitat que el configura. Per això, hem de continuar sent una veu activa de la societat civil, per damunt de tots aquells que ens voldrien mesells i muts.

Que creiem que la renovació pedagògica és cosa de cada dia, d'anar-la construint pas a pas, més des del centre que individualment $\mathrm{i}$ que sempre és preferible el petit avenç col.lectiu que no la gambada d'un de sol.

Que el nostre mètode de treball parteix de la reflexió col.lectiva que anem fent de la realitat de cada dia. EI nostre procés de treball es va fent i desfent en un diàleg engrescador que ens obliga a la recerca contínua i cada vegada més explícita i aprofundida.

Que som agents actius d'aquesta renovació i que l'entenem com una feina col.lectiva de tots els estaments que configuren la comunitat educativa.

Que no ens fa por l'existència dels conflictes dins la comunitat educativa, perquè creiem que entre tots sabrem trobar les maneres de resoldre'ls.

Que volem i necessitem el consens com a mètode principal en la presa de decisions.

Que estem disposats a posar damunt la taula la nostra reflexió i la nostra feina perquè pugui ser revisada $\mathrm{i}$ avaluada. Aquesta actitud oberta circula paral.lelament a l'exigència de revisar el paper i les actuacions de l'administració i de la societat en general, especialment en tot allò que fa referència als valors que volem fer vius a les escoles $i$ als recursos humans $i$ econòmics que ens són imprescindibles.

Que volem que cada escola trobi el seu camí per millorar el seu treball. Això significa que cal potenciar els projectes educatius, l'autonomia dels centres, la diversitat dels models de gestió, la xarxa de relació amb l'entorn i la interrelació amb tot el teixit social.

Que la formació permanent del professorat és un dels eixos de la qualitat de l'escola i volem incidir-hi plenament, fent possible un model plural, que equilibri el paper que ha de tenir l'administració i el que pot i vol tenir el professorat i la comunitat educativa en general. Que volem que amb aquesta formació es desenvolupi el nivell cosntructiu de les relacions humanes.

Que hem de ser exigents en el paper estimulant $\mathrm{i}$ motivador que ha de tenir l'administració i la societat per fer que l'escola progressi.

Que volem afirmar que la petita creativitat de cada dia i les petites iniciatives fan que les escoles esdevinguin llocs de cultura i de treball, llocs on els seus participants esdevenen homes i dones de bé que volen construir un món més just i més solidari.

Que estimem la nostra feina i que continuarem afirmant què som i en què creiem.

PER TOT AIXÒ, ENS ADHERIM A LA CONVOCATÒRIA DEL PRIMER CONGRÉS DE LA RENOVACIÓ PEDAGÓGICA, COM A FITA D'UN PROCÉS QUE VOLEM ENDEGAR ARA. UN

PROCÉS QUE PUGUI INCORPORAR I ARTICULAR TOTES LES INICIATIVES, EXPERIĖNCIES, PROJECTES I PROPOSTES DE MILLORA EDUCATIVA I UN PROCÉS QUE ESTIMULI LA SOCIETAT CIVIL, L'ADMINISTRACIÓ I TOTS ELS ENSENYANTS A SER RIGOROSOS, EXIGENTS I AUTOEXIGENTS I A NO CLAUDICAR EN L'OBJECTIU DE MILLORAR L'EDUCACIÓ DE TOTS ELS NENS I LES NENES, NOIS I NOIES DE CATALUNYA.

Lloret de Mar, 8 de novembre del 1992

\section{Grams o Tones de Renovació}

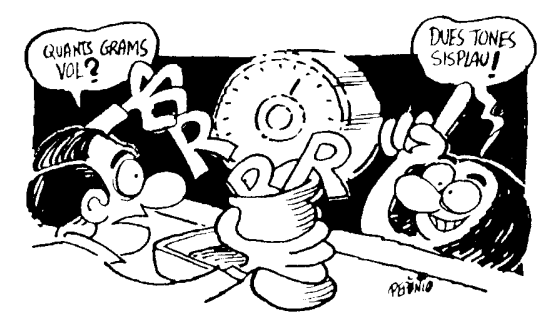

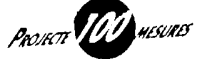

Moviments de Renovacio Pedagógica de Catalunyo 